\title{
Structure Variation from One-Dimensional Chain to Three-Dimensional Architecture: Effect of Ligand on Construction of Lanthanide Coordination Polymers
}

\author{
LEI WANG*, WEN-XUAN LI, XIAO-MIN GU, WEN-LI ZHANG and LIANG NI \\ School of Chemistry and Chemical Engineering, Jiangsu University, Zhenjiang 212013, \\ People's Republic of China \\ Email: wanglei86@ujs.edu.cn
}

MS received 12 October 2016; revised 21 December 2016; accepted 3 January 2017

\begin{abstract}
Four lanthanide coordination polymers were constructed from mixed ligands of phenanthroline derivative and flexible polydentate ligands, $\left[\mathrm{Gd}_{2}(1,3-\mathrm{BDC})_{3}(\mathrm{MOPIP})_{2}\right]_{\mathrm{n}} \cdot \mathrm{nH}_{2} \mathrm{O}(\mathbf{1}),\left[\mathrm{Gd}(1,4-\mathrm{BDC})_{1.5}(\mathrm{MOPIP})\right]_{\mathrm{n}}(\mathbf{2})$, $\left[\mathrm{Yb}(1,4-\mathrm{BDC})_{1.5}(\mathrm{MOPIP})\right]_{\mathrm{n}}(\mathbf{3})$ and $\left[\mathrm{Sm}(1,4-\mathrm{BDC})_{1.5}(\mathrm{MOPIP})\right]_{\mathrm{n}}(\mathbf{4})$, (MOPIP $=2$-(4-methoxyphenyl)- $1 \mathrm{H}$ imidazo[4,5- $f][1,10]$ phenanthroline, 1,3-BDC = benzene-1,3- dicarboxylic acid, 1,4-BDC = benzene-1, 4-dicarboxylic acid). The polymers have been synthesized under hydrothermal conditions and structurally characterized by single crystal X-ray diffraction analysis. Compound $\mathbf{1}$ possesses one-dimensional chain structure, and expands into the three-dimensional supramolecular architecture by $\pi \cdots \pi$ stacking and hydrogen-bonding interactions. Meanwhile, compounds 2-4 exhibit three-dimensional frameworks with pcu topology $\left(4^{12} \cdot 6^{3}\right)$. The structural differences among such compounds show that the steric hindrances of benzene dicarboxylic acid ligands play a key role in the assembly and the structures of the title compounds. Compounds $\mathbf{1}$ and $\mathbf{2}$ act as efficient Lewis acid catalysts for the cyanosilylation of benzaldehyde in high yields, due to the strong Lewis acidity.
\end{abstract}

Keywords. Lanthanides; hydrothermal synthesis; crystal structure; cyanosilylation.

\section{Introduction}

The lanthanide ions not only have large radii and high coordination number but also display strong luminescence. These factors therefore have great potential in the synthesis of new luminescent materials. ${ }^{1,2}$ Because of the $4 f-4 f$ transitions $^{3,4}$ in the electronic configuration of lanthanide ions, luminescent properties are forbidden by spin and parity selection rules, and the absorption coefficients of lanthanide ions are very small. It is necessary to design or select coordinated organic ligands acting as metal sensitizers to enhance absorption. The organic ligands with large conjugated plane and rigid structure can enhance the luminescent intensity. ${ }^{5}$ So, we chose a derivative of 1,10-phenanthroline, 2-(4-methoxyphenyl)- $1 H$-imidazo[4,5- $f][1,10]$ phenanthroline (MOPIP) possessing an extended aromatic system, to construct the lanthanide coordination compounds. ${ }^{6-8}$

Joining a second ligand into the coordination compound will make the structure rich and innovative, which can also change the zero-dimensional into onedimensional molecule or one-dimensional chain into

*For correspondence two-dimensional layer structure by the functioning of the second ligand. Aromatic carboxylic acids are usually selected as the second ligand, which can bring many kinds of coordination modes with the lanthanide ion. Considering these aspects, benzene-1,3-dicarboxylic acid (1,3- $\left.\mathrm{H}_{2} \mathrm{BDC}\right)$ and benzene-1,4-dicarboxylic acid (1,4- $\left.\mathrm{H}_{2} \mathrm{BDC}\right)$, a kind of polydentate ligands, are adopted for synthesizing the compounds. They act as a linker with different steric hindrance effects to connect metal ions into various structures via a variety of coordination modes. Moreover, the lanthanide coordination compounds used for efficient Lewis acid catalysts for the cyanosilylation of benzaldehyde is still rare. In our work, we have employed the lanthanide coordination compounds as Lewis acid catalysts in the cyanosilylation reacton, in which high yields of the products were obtained.

Herein, the coordination of lanthanide ions with $\mathrm{H}_{2} \mathrm{BDC}$ and MOPIP under hydrothermal conditions ${ }^{9,10}$ produced a series of lanthanide coordination polymers, namely, $\left[\mathrm{Gd}_{2}(1,3-\mathrm{BDC})_{3}(\mathrm{MOPIP})_{2}\right]_{\mathrm{n}} \cdot \mathrm{nH}_{2} \mathrm{O} \quad(\mathbf{1}), \quad[\mathrm{Gd}$ $(1,4-B D C)_{1.5}($ MOPIP $\left.)\right]_{\mathrm{n}}(\mathbf{2}),\left[\mathrm{Yb}(1,4-\mathrm{BDC})_{1.5}(\mathrm{MOPIP})\right]_{\mathrm{n}}$ (3) and $\left[\operatorname{Sm}(1,4-B D C)_{1.5}(\mathrm{MOPIP})\right]_{\mathrm{n}}$ (4). Additionally, the luminescent properties and catalysis of cyanosilylation reactions have also been investigated. 


\section{Experimental}

\subsection{Materials and methods}

The neutral chelating ligand MOPIP was synthesized according to the literature method. ${ }^{11} \mathrm{LnCl}_{3} \cdot 6 \mathrm{H}_{2} \mathrm{O}[\mathrm{Ln}=\mathrm{Gd}(\mathbf{1 , 2})$, $\mathrm{Yb}(3) \mathrm{Sm}(4)], \mathrm{NaOH}$ and $\mathrm{H}_{2} \mathrm{BDC}$ were purchased commercially and used without further purification. Transmission mode FT-IR spectra were obtained as $\mathrm{KBr}$ pellets between 4000 and $400 \mathrm{~cm}^{-1}$ using a Nicolet Nexus 470 infrared spectrometer. Thermogravimetric analysis (TGA) was performed with a TA Instruments with a heating rate of $10^{\circ} \mathrm{C} \cdot \mathrm{min}^{-1}$ in nitrogen. Luminescence measurement was carried out at room temperature with a Cary Eclipse spectrometer.

\subsection{Synthesis of compounds 1-4}

2.2a $\left[G d_{2}(1,3-B D C)_{3}(M O P I P)_{2}\right]_{n} \cdot n H_{2} O(1)$ : A mixture of $\mathrm{GdCl}_{3} \cdot 6 \mathrm{H}_{2} \mathrm{O}(0.186 \mathrm{~g}, 0.5 \mathrm{mmol}), 1,3-\mathrm{H}_{2} \mathrm{BDC}(0.083 \mathrm{~g}$, $0.5 \mathrm{mmol}), \mathrm{MOPIP}(0.163 \mathrm{~g}, 0.5 \mathrm{mmol}), \mathrm{NaOH}(0.004 \mathrm{~g}$, $0.1 \mathrm{mmol})$ and $\mathrm{H}_{2} \mathrm{O}(18 \mathrm{~mL})$ was placed in a $25 \mathrm{~mL}$ Teflonlined stainless steel vessel under autogenous pressure at $165^{\circ} \mathrm{C}$ for five days. After cooling to room temperature, yellow block crystals of $\mathbf{1}$ were collected by filtration and washed with distilled water. Yield: $65 \%$ (based on MOPIP ligand). Anal. Calcd. (\%) for $1 \mathrm{C}_{64} \mathrm{H}_{40} \mathrm{~N}_{8} \mathrm{O}_{15} \mathrm{Gd}_{2}$ : C, 52.10; $\mathrm{H}, 2.73 ; \mathrm{N}, 7.59$. Found (\%): C, 52.09; H, 2.75; N, 7.57. IR $\left(\mathrm{KBr}, \mathrm{cm}^{-1}\right): 3603(\mathrm{~m}), 3075(\mathrm{~m}), 1616(\mathrm{~s}), 1528(\mathrm{~s}), 1486(\mathrm{~s})$, 1399 (s), 1258 (m), 1181 (m), 1076 (m), 841 (m), 743 (m), $531(\mathrm{w}), 400(\mathrm{w}) \mathrm{cm}^{-1}$.

2.2b $\quad\left[G d(1,4-B D C)_{1.5}(M O P I P)\right]_{n}(2): \quad$ The preparation of 2 was similar to that of $\mathbf{1}$ except that $1,4-\mathrm{H}_{2} \mathrm{BDC}(0.083 \mathrm{~g}$, $0.5 \mathrm{mmol})$ was used instead of $1,3-\mathrm{H}_{2} \mathrm{BDC}$. After cooling to room temperature, yellow block crystals of $\mathbf{2}$ were collected. Yield: $62 \%$ (based on MOPIP ligand). Anal. Calcd. (\%) for $2 \mathrm{C}_{32} \mathrm{H}_{20} \mathrm{~N}_{4} \mathrm{O}_{7} \mathrm{Gd}: \mathrm{C}, 52.67 ; \mathrm{H}, 2.76 ; \mathrm{N}, 7.68$. Found (\%): $\mathrm{C}$, 52.68; H, 2.78; N, 7.66. IR (KBr, $\left.\mathrm{cm}^{-1}\right)$ : 3067 (m), 1684 (s), $1610(\mathrm{~m}), 1509(\mathrm{~m}), 1480(\mathrm{~m}), 1398(\mathrm{~s}), 1289(\mathrm{~m}), 1173(\mathrm{~m})$, $1019(\mathrm{~m}), 834(\mathrm{w}), 782(\mathrm{~m}), 512(\mathrm{w}), 419(\mathrm{w}) \mathrm{cm}^{-1}$.

2.2c $\quad\left[Y b(1,4-B D C)_{1.5}(M O P I P)\right]_{n}(3): \quad$ The preparation of $\mathbf{3}$ was similar to that of 2 except that $\mathrm{YbCl}_{3} \cdot 6 \mathrm{H}_{2} \mathrm{O}(0.190 \mathrm{~g}$, $0.5 \mathrm{mmol}$ ) was used instead of $\mathrm{GdCl}_{3} \cdot 6 \mathrm{H}_{2} \mathrm{O}$. After cooling to room temperature, yellow block crystals of $\mathbf{3}$ were collected. Yield: $60 \%$ (based on MOPIP ligand). Anal. Calcd. (\%) for $3 \mathrm{C}_{32} \mathrm{H}_{20} \mathrm{~N}_{4} \mathrm{O}_{7} \mathrm{Yb}: \mathrm{C}, 51.55 ; \mathrm{H}, 2.70 ; \mathrm{N}, 7.51$. Found (\%): $\mathrm{C}$, 51.53; H, 2.72; N, 7.53. IR ( KBr, $\left.\mathrm{cm}^{-1}\right): 3082(\mathrm{~m}), 1643(\mathrm{~m})$, $1612(\mathrm{~m}), 1526(\mathrm{~m}), 1485(\mathrm{~m}), 1400(\mathrm{~s}), 1254(\mathrm{~m}), 1177(\mathrm{~m})$, $1076(\mathrm{~m}), 812(\mathrm{~m}), 750(\mathrm{~m}), 514(\mathrm{w}), 441(\mathrm{w}) \mathrm{cm}^{-1}$.

2.2d $\left[\operatorname{Sm}(1,4-B D C)_{1.5}(M O P I P)\right]_{n}(\mathbf{4}): \quad$ The preparation of $\mathbf{4}$ was similar to that of 2 except that $\mathrm{SmCl}_{3} \cdot 6 \mathrm{H}_{2} \mathrm{O}(0.186 \mathrm{~g}$, $0.5 \mathrm{mmol}$ ) was used instead of $\mathrm{GdCl}_{3} \cdot 6 \mathrm{H}_{2} \mathrm{O}$. After cooling to room temperature, yellow block crystals of $\mathbf{4}$ were collected. Yield: $60 \%$ (based on MOPIP ligand). Anal. Calcd. (\%) for
$4 \mathrm{C}_{32} \mathrm{H}_{20} \mathrm{~N}_{4} \mathrm{O}_{7} \mathrm{Sm}: \mathrm{C}, 53.17 ; \mathrm{H}, 2.79 ; \mathrm{N}, 7.75$. Found (\%): C, 53.16; H, 2.81; N, 7.72. IR ( $\left.\mathrm{KBr}, \mathrm{cm}^{-1}\right): 3151(\mathrm{~m}), 1627$ (s), $1588(\mathrm{~m}), 1525(\mathrm{~m}), 1485(\mathrm{~m}), 1397(\mathrm{~s}), 1255(\mathrm{~m}), 1177(\mathrm{~m})$, $1075(\mathrm{~m}), 838(\mathrm{~m}), 748(\mathrm{~m}), 512(\mathrm{w}), 414(\mathrm{w}) \mathrm{cm}^{-1}$.

\section{$2.3 X$-ray crystallography}

Single-crystal X-ray data were collected at room temperature with a SMART APEX CCD diffractometer equipped with a graphite-monochromatic Mo-K $\alpha$ radiation $(\lambda=$ $0.71073 \AA$ ) by using an $\varphi-\omega$ scan mode at 293(2) K. The structures were solved by direct methods with SHELXS-97 program $^{12}$ and refined by SHELXL-9 $97^{13}$ using full-matrix least-squares techniques on $F^{2}$. All non-hydrogen atoms were refined anisotropically, the $\mathrm{H}$ atoms from the nitrogen atom of imidazole ring in MOPIP were located in different Fourier synthesis maps, and other hydrogen atoms of the ligands were generated theoretically onto the specific atoms and refined isotropically with fixed thermal factors. The H-atoms of water molecules have not been localized. The detailed crystallographic data and structure refinement parameters for the compounds 1-4 are summarized in Table 1 .

\subsection{Catalytic test for cyanosylation reaction}

A $10 \mathrm{~mL}$ vial with screw-cap was charged with benzaldehyde $(1.0 \mathrm{mmol})$ and trimethylsilyl cyanide (TMSCN, $2.0 \mathrm{mmol})$, and finally with the dissolved compound (1-4) $(2.5 \mathrm{~mol} \%)$. The reaction was carried out for $12 \mathrm{~h}$ with ultrasound in the sealed vial. After the reaction was completed, the catalyst was removed by centrifugation and then washed quickly with ethyl acetate. The conversion of benzaldehyde was observed by gas chromatographic analysis (GC, Agilent 7890A) and comparison of GC-MS (HP 6890) spectra with those of authentic samples.

\section{Results and Discussion}

\subsection{Structural analysis of compounds 1-4}

3.1a Crystal structure of $\left[G d_{2}(1,3-B D C)_{3}(M O P I P)_{2}\right]_{n}$. $n \mathrm{H}_{2} \mathrm{O}(1)$ : Single-crystal X-ray diffraction reveals that complex 1 consists of two Gd(III) ions, two MOPIP ligands, three $1,3-\mathrm{BDC}^{2-}$ anions, along with one water molecule. As shown in Figure 1a, each Gd(III) ion is eight-coordinated and surrounded by two nitrogen donors from a chelating MOPIP ligand, six oxygen atoms from five carboxylic groups of five different 1,3$\mathrm{BDC}^{2-}$ ligands. Chelating the MOPIP ligand makes a bite angle of $64.0^{\circ}(\mathrm{N} 1-\mathrm{Gd} 1-\mathrm{N} 2)$ and contributes distortion of the coordination geometry around the $\mathrm{Gd}(\mathrm{III})$ ion. The distances Gd-N (2.529(6) and 2.565(6) $\AA$ ), and Gd-O (2.291(5)-2.596(6) $\AA$ ) fall in the reported range. ${ }^{14}$

In compound $\mathbf{1}$, the $1,3-\mathrm{BDC}^{2-}$ anions exhibit two differences in their connectivity with Gd(III) ions. Out 
Table 1. Crystal Data and Structure Refinements for Compounds 1-4.

\begin{tabular}{lcccc}
\hline Compound & $\mathbf{1}$ & $\mathbf{2}$ & $\mathbf{3}$ & $\mathbf{4}$ \\
\hline Empirical formula & $\mathrm{C}_{64} \mathrm{H}_{40} \mathrm{~N}_{8} \mathrm{O}_{15} \mathrm{Gd}_{2}$ & $\mathrm{C}_{32} \mathrm{H}_{20} \mathrm{~N}_{4} \mathrm{O}_{7} \mathrm{Gd}$ & $\mathrm{C}_{32} \mathrm{H}_{20} \mathrm{~N}_{4} \mathrm{O}_{7} \mathrm{Yb}$ & $\mathrm{C}_{32} \mathrm{H}_{20} \mathrm{~N}_{4} \mathrm{O}_{7} \mathrm{Sm}$ \\
Formula weight & 1475.54 & 729.77 & 745.56 & 722.87 \\
Crystal system & Monoclinic & Monoclinic & Monoclinic & Monoclinic \\
Space group & $P 2_{1} / \mathrm{m}$ & $C 2 / \mathrm{c}$ & $C 2 / \mathrm{c}$ & $C 2 / \mathrm{c}$ \\
$a / \AA$ & $9.777(2)$ & $32.414(8)$ & $32.117(3)$ & $32.570(4)$ \\
$b / \AA$ & $18.152(4)$ & $9.7471(19)$ & $9.8188(9)$ & $9.8120(13)$ \\
$c / \AA$ & $17.163(6)$ & $18.998(4)$ & $18.7539(18)$ & $19.107(3)$ \\
$\alpha /{ }^{\circ}$ & 90 & 90 & 90 & 90 \\
$\beta /{ }^{\circ}$ & $106.30(3)$ & $112.80(3)$ & $112.6590(10)$ & $112.8740(10)$ \\
$\gamma /{ }^{\circ}$ & 90 & 90 & 90 & 90 \\
$V / \AA^{3}$ & $2923.6(10)$ & $5533(2)$ & $5457.6(9)$ & $5626.1(13)$ \\
$Z$ & 2 & 8 & 8 & 8 \\
$D c / \mathrm{g} . \mathrm{cm}$ & 1.676 & 1.761 & 1.815 & 1.707 \\
$F(000)$ & 1456 & 2880 & 2928 & 2864 \\
$R_{i n t}$ & 0.0499 & 0.0658 & 0.0152 & 0.0216 \\
$\mathrm{GOF}$ on $F^{2}$ & 1.118 & 1.059 & 1.385 & 1.177 \\
$R_{1}^{a}[I>2 \sigma(I)]$ & 0.0705 & 0.0391 & 0.0152 & 0.0249 \\
$w R_{2}^{b}[I>2 \sigma(I)]$ & 0.1585 & 0.0886 & 0.0474 & 0.0747 \\
\hline${ }^{a} R_{1}=\sum \| F_{o}|-| F_{c}|| / \sum\left|F_{o}\right|{ }^{b} w R_{2}$ & $\left\{\sum w\left(\left|F_{o}\right|^{2}-\left|F_{c}\right|^{2}\right)^{2} / \sum\left[w\left(\left|F_{o}\right|^{2}\right)\right]^{2}\right\}^{1 / 2}$.
\end{tabular}

of two differences present in 1,3-BDC ${ }^{2-}$ anions, the two carboxylic groups are coordinated in a chelating bidentate mode (coordination mode (a)) in one 1,3-BDC ${ }^{2-}$ anion, whereas the other is coordinated in a bridging bidentate mode as depicted in Scheme 1 (coordination mode (b)). Two crystallographically equivalent $\mathrm{Gd}^{3+}$ ions are bridged by four carboxylic groups in bidentate fashion, and form a dinuclear lanthanide building block $\left[\mathrm{Gd}_{2} \mathrm{~N}_{4} \mathrm{O}_{8}\right]$ (Figure 1b). The dinuclear lanthanide building blocks are connected to each other through 1,3-BDC ${ }^{2-}$ anions leading to a three-stranded zipper chain. The terminal MOPIP ligands lie on both sides of the chain and restrict the growth of the chain in a straightforward way (Figure 1c).

Significant $\pi$ interactions are also implicated for the assembly of the crystal lattice. Complex 1 exhibits two different $\pi \cdots \pi$ interactions. The first $\pi \cdots \pi$ stacking interaction is offset face-to-face $\pi \cdots \pi$ stacking interaction between imidazole rings and terminal benzene units of MOPIP ligands in the adjacent chains at a centroid-to-face distance of 3.7820(9) $\AA$. The second interaction occurs between $1,3-\mathrm{BDC}^{2-}$ anions and phen rings of the MOPIP ligands in one chain with an edgeto-face fashion at a distance of 3.6835(9) $\AA$. The $\pi \cdots \pi$ stacking interaction is shown in Figure 1d, which assemble the neighboring chain into a corrugated network. Additionally, the neighboring MOPIP ligands and $1,3-\mathrm{BDC}^{2-}$ anions also are joined by $\mathrm{N}-\mathrm{H} \cdots \mathrm{O}$ hydrogen bonds (Table 2). The weak C-H...O hydrogen-bonding interactions between MOPIP and 1,3$\mathrm{BDC}^{2-}$ anions have been also observed in $\mathbf{1}$ (Table 2), as shown in Figure 1e. Obviously, the strong aromatic $\pi \cdots \pi$ stacking and hydrogen-bonding interactions play an important role in stabilizing the supramolecular architecture.

3.1b Crystal structure of $\left[G d(1,4-B D C)_{1.5}(M O P I P)\right]_{n}$ (2), $\left[Y b(1,4-B D C)_{1.5}(M O P I P)\right]_{n}(3)$ and $\left[\operatorname{Sm}(1,4-B D C)_{1.5}\right.$ $(M O P I P)]_{n}(4)$ : To evaluate the influence of the position of carboxylic groups on the framework formation of the complex, we selected $1,4-\mathrm{H}_{2} \mathrm{BDC}$ to react with lanthanide metal salt in the presence of the same $\mathrm{N}$-donor ligand and obtained compound 2. Compound $\mathbf{2}$ has a three-dimensional network structure. As shown in Figure 2a, each Gd(III) center is coordinated by five carboxylic groups of 1,4-BDC ligand and a chelating MOPIP ligand. Thus, each Gd(III) center is eight-coordinated in a distorted dodecahedral geometry consisting of two nitrogen atoms from the MOPIP ligand and six oxygen atoms from five different 1,4$\mathrm{BDC}^{2-}$ ligands.

The carboxylate group present in the $1,4-\mathrm{BDC}^{2-}$ ligand acts in two different coordination modes as shown in Scheme 2 (coordination modes $\mathrm{c}$ and d). The first type is essentially bridging bimonodentate mode and bridges two Gd(III) centers separated at a distance of $4.2384 \AA$ (Figure $2 b$ ), which results in the formation of dinuclear paddle-wheel building block. The second type is chelating bidentate mode. Each building block is connected by adjacent six building blocks through these modes to generate an extended three-dimensional framework (Figures $2 b$ and $2 c$ ). To 

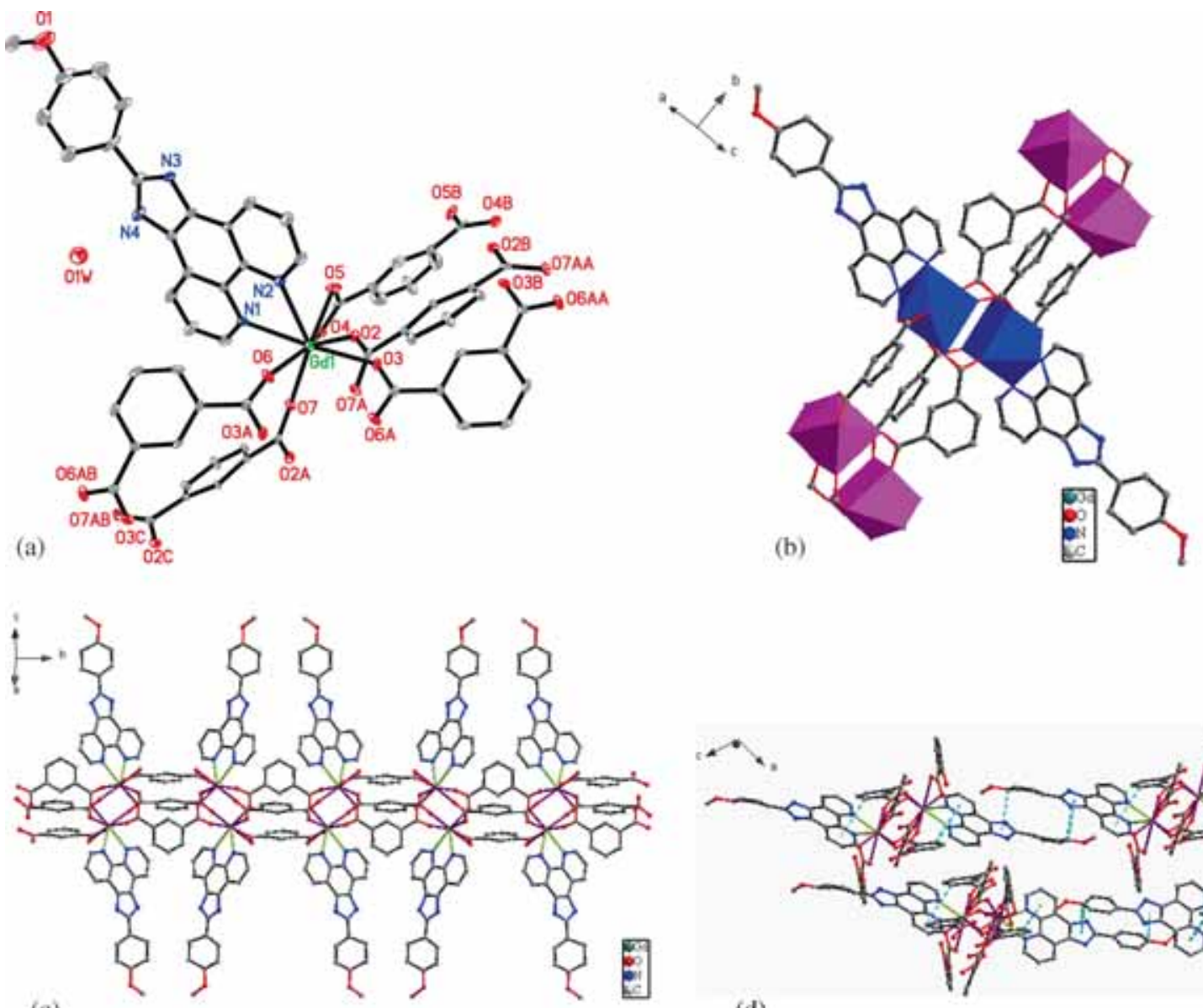

(c)
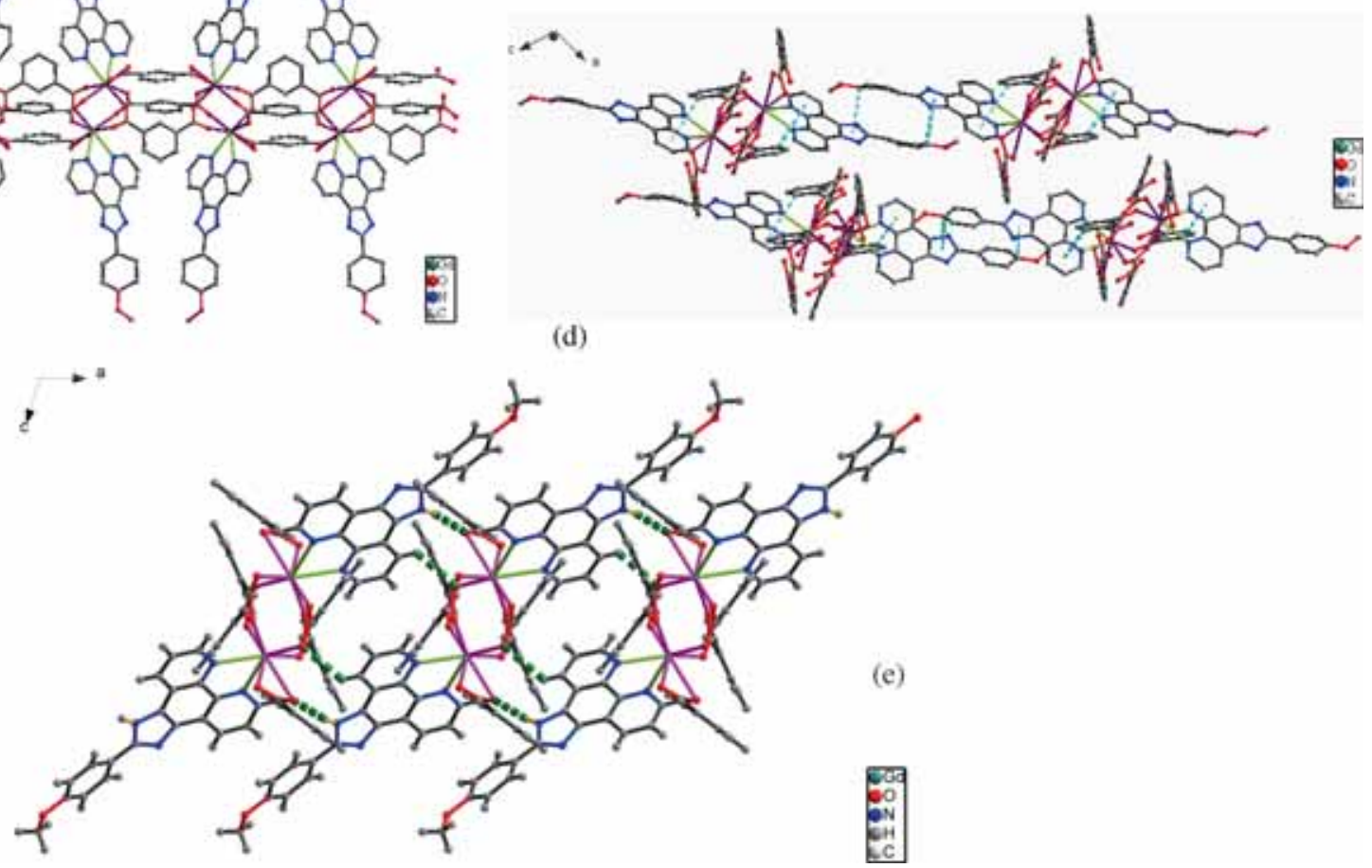

(d)

(e)

Figure 1. (a) View of the coordination environment of Gd(III) in complex 1; thermal ellipsoids are drawn at the 30\% probability level. Hydrogen atoms have been omitted for clarity. (b) View of the linkage of the dinuclear core with four adjacent cores ( $\mathrm{H}$ atoms and part of the aromatic rings are omitted for clarity) (c) The $1 \mathrm{D}$ chain network of 1 along $\mathrm{b}$ axis. (d) The 2D layer architecture by $\pi \ldots \pi$ stacking interactions (blue broken lines represent $\pi \ldots \pi$ stacking interactions). (e) The 3D supramolecular architecture by hydrogen bonding interactions (green broken lines represent hydrogen bonding interactions).

better understand the structure of $\mathbf{2}$, dinuclear building blocks are defined as 6-connected nodes, and 1,4$\mathrm{BDC}^{2-}$ can act as spacers. On the basis of this simplification, the structure of $\mathbf{2}$ can be described as a sixconnected three-dimensional network with the Schlafli symbol $\left(4^{12} \cdot 6^{3}\right)$, which corresponds to a $p c u$ topology. ${ }^{15}$ In addition, the MOPIP ligands in compound $\mathbf{2}$ act as hydrogen bond donors to the coordinated oxygen atoms of 1,4-BDC ${ }^{2-}$ anions and exhibit one kind of $\mathrm{N}-$ $\mathrm{H}$. . O hydrogen-bonding interaction. The other kind of hydrogen-bonding is weak $\mathrm{C}-\mathrm{H} \cdots \mathrm{O}$ interaction. Inter $\mathrm{N}-\mathrm{H} \cdots \mathrm{O}$ and $\mathrm{C}-\mathrm{H} \cdots \mathrm{O}$ hydrogen bonds (Table 2) also stabilize the three-dimensional supramolecular structure (Figure 2d). The structure of compound $\mathbf{2}$ 


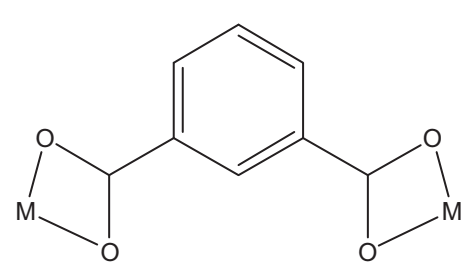

(a)

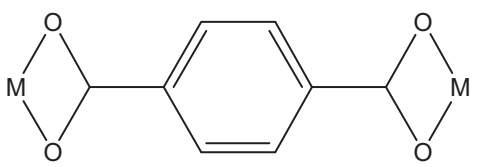

(c)

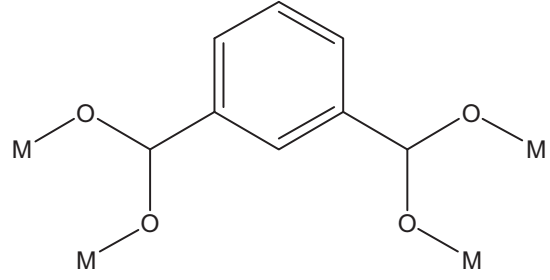

(b)

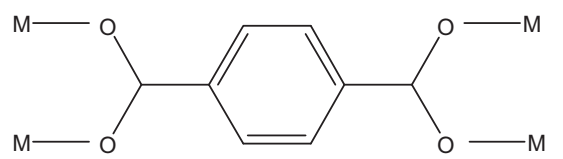

(d)

Scheme 1. Coordination modes of $\mathrm{BDC}^{2-}$ groups in compounds $\mathbf{1}$ and $\mathbf{2}$.

Table 2. Hydrogen Bond Lengths $(\AA)$ and Bond Angles $\left({ }^{\circ}\right)$ for compounds 1-2.

\begin{tabular}{lcccc}
\hline Compound 1 & & & & \\
$\mathrm{D}-\mathrm{H} \cdots \mathrm{A}$ & $\mathrm{D}-\mathrm{H} / \AA$ & $\mathrm{H} \cdots \mathrm{A} / \AA$ & $\mathrm{D} \cdots \mathrm{A} / \AA$ & $\mathrm{D}-\mathrm{H} \cdots \mathrm{A} / \mathrm{deg}$ \\
$\mathrm{N}(3)-\mathrm{H}(3 \mathrm{~A}) \cdots \mathrm{O}(4)$ & 0.86 & 1.93 & $2.761(0)$ & 164 \\
$\mathrm{C}(8)-\mathrm{H}(8 \mathrm{~A}) \cdots \mathrm{O}(3) \mathrm{A}$ & 0.93 & 2.57 & $3.228(7)$ & 129 \\
Compound 2 & & & & \\
$\mathrm{D}-\mathrm{H} \cdots \mathrm{A}$ & $\mathrm{D}-\mathrm{H} / \AA$ & $\mathrm{H} \cdots \mathrm{A} / \AA$ & $\mathrm{D} \cdots \mathrm{A} / \AA$ & $\mathrm{D}-\mathrm{H} \cdots \mathrm{A} / \mathrm{deg}$ \\
$\mathrm{N}(4)-\mathrm{H}(4 \mathrm{~A}) \cdots \mathrm{O}(4) \mathrm{B}$ & 0.86 & 2.05 & $2.886(7)$ & 165 \\
$\mathrm{C}(3)-\mathrm{H}(3 \mathrm{~A}) \cdots \mathrm{O}(2) \mathrm{B}$ & 0.93 & 2.55 & $3.163(8)$ & 124 \\
\end{tabular}

*Symmetry code: A: $1+x, y, z ; B: x, 1+y, z$.

possesses large voids containing a considerable number of diffuse electron density peaks that could not be adequately modeled as solvent. PLATON analysis ${ }^{16}$ shows that total potential solvent accessible void volume is $207.9 \AA^{3}$, accounting for $3.8 \%$ of the total cell volume.

Compounds $\mathbf{2 , 3}$ and $\mathbf{4}$ are isostructural, and therefore only the structure of $\mathbf{2}$ will be described in detail.

\subsection{Effect of Carboxylate Ligands on the Structures of the Compounds}

According to the previous reports, carboxylate ligands play an important role in the formation of coordination architectures. Two divergent MOPIP-Gd(III) compounds, 1 and $\mathbf{2}$ were successfully obtained by changing carboxylate ligands (1,3-BDC and 1,4-BDC) in the presence of the same MOPIP ligand and $\mathrm{Gd}^{3+}$ ions. The only difference in the two dicarboxylic acids is the position of the carboxyl group, and which have $120^{\circ}$, $180^{\circ}$ angles, respectively. The framework of $\mathbf{1}$ is formed by dinuclear lanthanide building block, and dinuclear lanthanide building blocks are connected to each other through three 1,3-BDC ligands leading to a zipper chain. The framework of $\mathbf{2}$ is composed of the same dinuclear lanthanide building blocks. However, owing to the small steric hindrances of 1,4-BDC, dinuclear lanthanide building blocks are interconnected through one 1,4-BDC ligand to generate an extended three-dimensional framework. Obviously, the second ligand possessing different steric hindrance makes the structures of compounds $\mathbf{1}$ and $\mathbf{2}$ to be different, rich and colorful.

\subsection{FT-IR Analysis}

The FT-IR spectra of the compounds 1-4 exhibit strong characteristic absorptions for the carboxylic groups of the $\mathrm{BDC}^{2-}$ in the asymmetric and symmetric vibration regions. The asymmetric stretching vibrations $v_{\text {asym }}\left(\mathrm{COO}^{-}\right)$appear in the range of $1588-1616 \mathrm{~cm}^{-1}$, while the symmetric stretching vibrations $v_{\text {sym }}\left(\mathrm{COO}^{-}\right)$ are observed from $1397-1400 \mathrm{~cm}^{-1}$. The frequency shift to lower values may be due to the connection with lanthanide ions. ${ }^{17,18}$ Meanwhile, the $v(\mathrm{C}=\mathrm{N})$ vibration of the ligand MOPIP shifts to lower wave number around $1509-1528 \mathrm{~cm}^{-1}$ in the spectra, demonstrating coordination of nitrogen atoms to lanthanide ions. ${ }^{19}$ The signal at $511-531 \mathrm{~cm}^{-1}$ also proves the coordination of lanthanide ions and nitrogen atoms. The band 

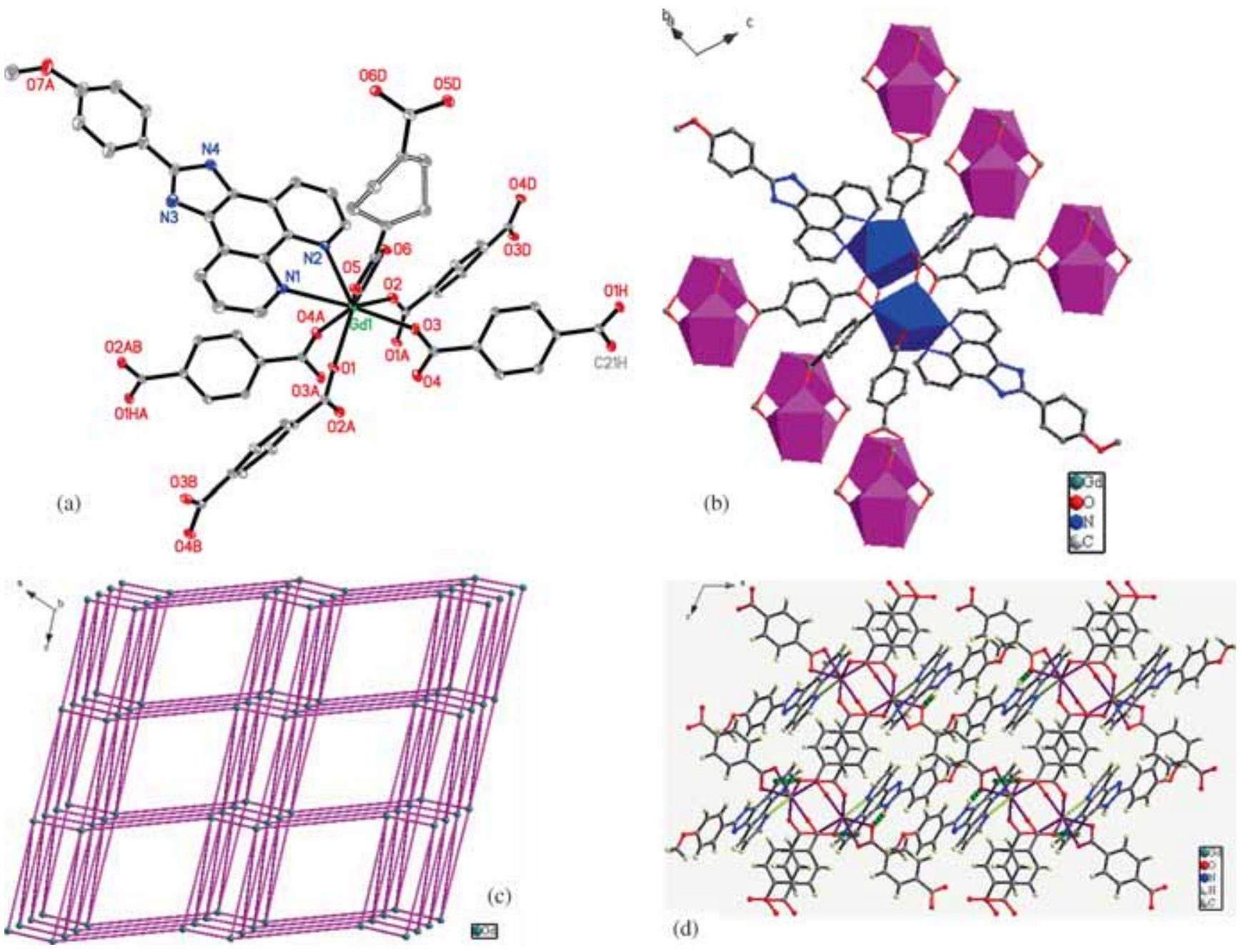

Figure 2. (a) View of the coordination environment of Gd(III) in complex 2; thermal ellipsoids are drawn at the 30\% probability level. Hydrogen atoms have been omitted for clarity. (b) View of the linkage of the dinuclear core with six adjacent cores (H atoms and part of the aromatic rings are omitted for clarity). (c) Schematic representation of the 6-connected net with a $\left(4^{12} \cdot 6^{3}\right)$ topology. (d) The 3D supramolecular architecture by hydrogen bonding interactions (green broken lines represent hydrogen bonding interactions).

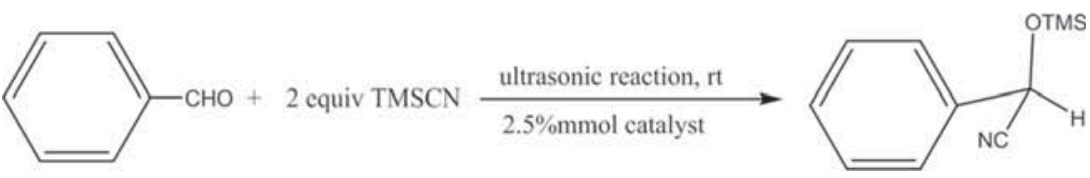

Scheme 2. Cyanosilylation Reaction in the Presence of Four compounds.

at $400-441 \mathrm{~cm}^{-1}$ indicates that the lanthanide ions are coordinated with oxygen atoms. ${ }^{20}$ The broad bands around $3600 \mathrm{~cm}^{-1}$ for compound $\mathbf{1}$ are attributed to the vibrations of water molecules.

\subsection{Thermal properties}

Thermal stability of the compounds 1-4 were examined by using thermogravimetric (TG) analyzer.
Compounds 2, 3 and $\mathbf{4}$ are isostructural, with the same TG curves, and therefore only compounds $\mathbf{1}$ and $\mathbf{2}$ were selected for discussion. From the TG curve (Figure 3), compound 1 shows a three-step weight loss. The first weight loss of $1.91 \%$ (calc. $1.25 \%$ ) is assigned to the liberation of water molecule. The second weight loss of $37.45 \%$ (calc $33.60 \%$ ) between 432 and $574^{\circ} \mathrm{C}$ is ascribed to the loss of 1,3-BDC ${ }^{2-}$ ligand. The last loss of $39.01 \%$ (calc. $43.99 \%$ ) occurs from 574 to $1300^{\circ} \mathrm{C}$, 
which corresponds to the loss of MOPIP ligand. For compound 2, the framework begins to collapse at $532^{\circ} \mathrm{C}$, which is ascribed to the removal of $1,4-\mathrm{BDC}^{2-}$ ligand (obsd. 30.58\%, calcd. 34.02\%). The departure of MOPIP ligand occurs from 612 to $1300^{\circ} \mathrm{C}$ (obsd. $45.48 \%$, calc. $44.54 \%$ ). The observed total weight is in agreement with the theoretical value of the crystal structure, with $\mathrm{Gd}_{2} \mathrm{O}_{3}$ formed as the final remnant.

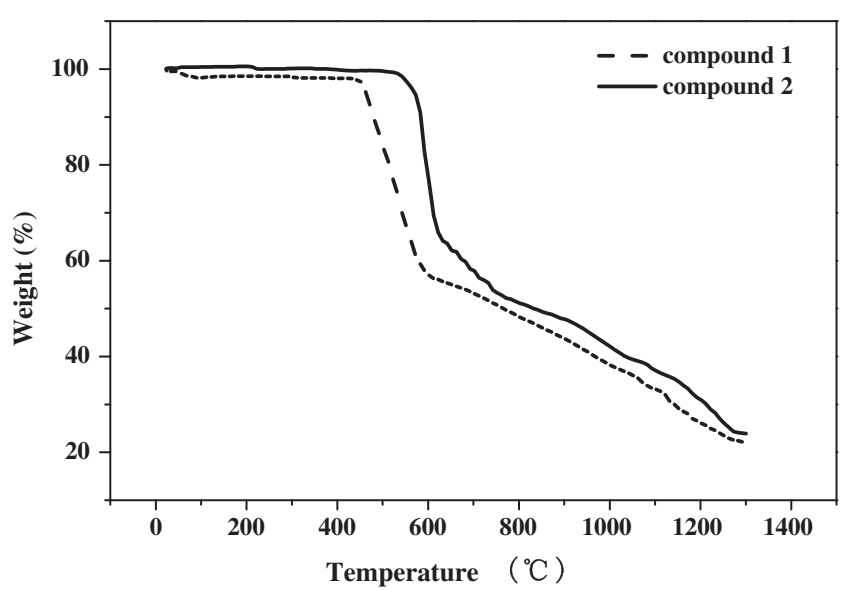

Figure 3. TG curves of compounds $\mathbf{1}$ and 2.

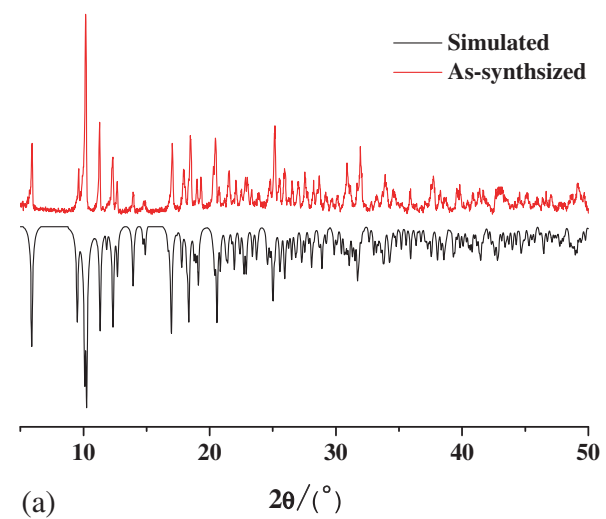

(a)

$2 \theta /\left(^{\circ}\right)$

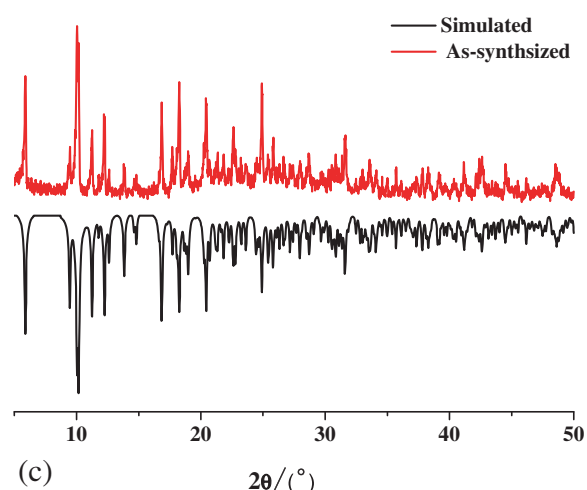

(c)

$2 \theta /\left(^{\circ}\right)$

Figure 4. Comparison of PXRD patterns of the simulated pattern from the singlecrystal structure determination and the as-synthesized products of compounds $\mathbf{2}$ (a), $\mathbf{3}$ (b) and 4 (c) as powder.

\subsection{Powder X-ray Diffraction Analyses}

To confirm the phase purity of the bulk materials, the powder X-ray diffraction (PXRD) experiments were carried out for complexes 1-4. The PXRD pattern of compounds $\mathbf{1}$ and $\mathbf{2}$ were same, therefore only complex 2 was selected as example. As shown in Figure 4, the PXRD pattern of complexes 2-4 are in good agreement with those simulated from their single crystal structure. The differences in reflection intensities between the simulated and the experimental patterns may be due to the variation in preferred orientation of the powder samples. ${ }^{21}$

\subsection{Luminescent Property}

Since the compounds were found insoluble in common solvents, luminescent properties of pure ligand MOPIP and the compounds 1-4 were recorded in the solid state at room temperature. The pure ligand MOPIP presents a strong emission with the band at $467 \mathrm{~nm}\left(\lambda_{e x}=361 \mathrm{~nm}\right)$, which could be attributed to the $\pi * \rightarrow \pi$ transition of the large $\pi$-conjugated system ${ }^{22}$ (Figure S1 in Supplementary Information). The emission spectra of compounds $\mathbf{1}$ and $\mathbf{2}$ display spectra

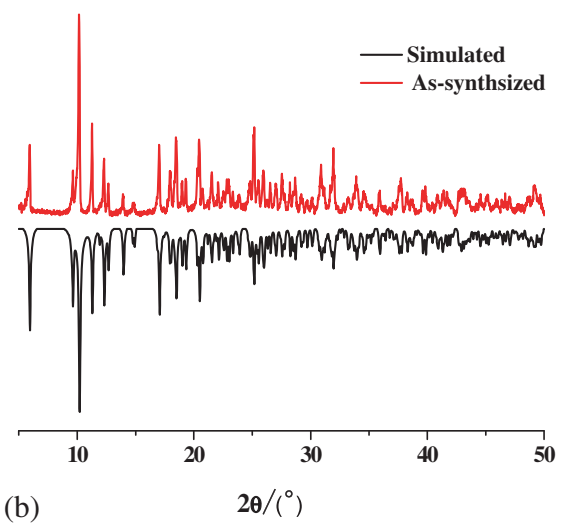

(b) 

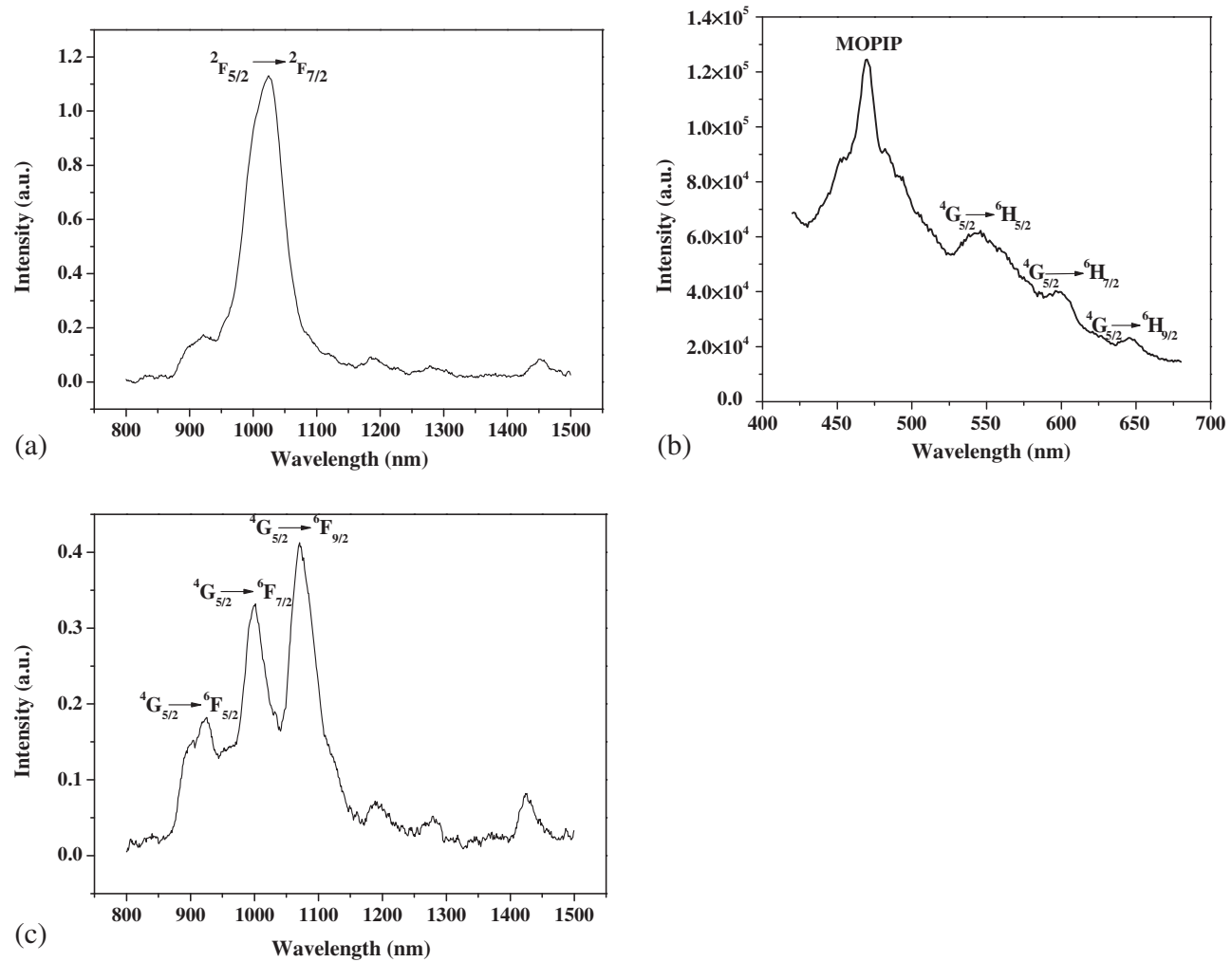

Figure 5. Luminescent emission spectra of compound 3 (a) in near-infrared region (upon excitation at $361 \mathrm{~nm}$ ), 4 (b) in visible region (upon excitation at $361 \mathrm{~nm}$ ) and $\mathbf{4}$ (c) in nearinfrared region (upon excitation at $428 \mathrm{~nm}$ ) in the solid state at room temperature.

Table 3. The Catalytic Activities for Four Compounds (yield ${ }^{\mathrm{a}}$ and $\mathrm{TOF}^{\mathrm{b}}$ ).

\begin{tabular}{lcc}
\hline & Yield $(\%)^{\mathrm{a}}$ & $\mathrm{TOF}\left(\mathrm{h}^{-1}\right)^{\mathrm{b}}$ \\
\hline Compound 1 & 96.41 & 38.56 \\
Compound 2 & 97.86 & 39.14 \\
Compound 3 & 41.27 & 16.51 \\
Compound 4 & 77.97 & 31.19 \\
\hline
\end{tabular}

${ }^{\mathrm{a}}$ Yield determined by GC-MS; ${ }^{\mathrm{b}} \mathrm{TOF}=($ yield $) /((\mathrm{mol} \%$ catalyst) t).

similar to those of the ligand MOPIP (Figure S2 in SI), partly due to the fact that the ligand MOPIP is difficult to sensitize the luminescence of $\mathrm{Gd}(\mathrm{IIII})^{23}$ ion. As shown in Figure 5, compound 3 shows a maximum emission band at $1023 \mathrm{~nm}$ when excited at $361 \mathrm{~nm}$, which results from the ${ }^{2} \mathrm{~F}_{5 / 2} \rightarrow{ }^{2} \mathrm{~F}_{7 / 2}$ transition. ${ }^{24}$ It indicates that MOPIP ligand may effectively sensitize the near-infrared luminescence of $\mathrm{Yb}$ (III) ion. In compound 4, characteristic luminescence of $\mathrm{Sm}$ (III) ion are found, which are ${ }^{4} \mathrm{G}_{5 / 2} \rightarrow{ }^{6} \mathrm{H}_{5 / 2}(548 \mathrm{~nm}),{ }^{4} \mathrm{G}_{5 / 2} \rightarrow{ }^{6} \mathrm{H}_{7 / 2}$ $(598 \mathrm{~nm}),{ }^{4} \mathrm{G}_{5 / 2} \rightarrow{ }^{6} \mathrm{H}_{9 / 2}(644 \mathrm{~nm}){ }^{25}$ transitions, respectively. Meanwhile, the strong emission peak at $467 \mathrm{~nm}$ belongs to MOPIP ligand. However, the emission intensity for Sm(III) ions is lower than that MOPIP ligand, which implies that the efficiency of energy transfer from ligand to $\mathrm{Sm}$ (III) ion is low. ${ }^{26,27}$ The luminescence of $\mathrm{Sm}$ (III) ions in near-infrared region were also tested under the excitation at $428 \mathrm{~nm}$. Sm(III) compound displays emission bands at 925, 1001 and $1071 \mathrm{~nm}$, which are attributed to the transitions from ${ }^{4} \mathrm{G}_{5 / 2} \rightarrow{ }^{6} \mathrm{~F}_{5 / 2}^{4}$, $\mathrm{G}_{5 / 2} \rightarrow{ }^{6} \mathrm{~F}_{7 / 2}$ and ${ }^{4} \mathrm{G}_{5 / 2} \rightarrow{ }^{6} \mathrm{~F}_{9 / 2}$, respectively. ${ }^{28}$

\subsection{Catalytic tests}

We adopted the cyanosilylation reaction to test the Lewis acid catalysis of the four compounds (Scheme 2). ${ }^{29}$ The reaction products, cyanohydrin derivatives, are important components in the synthesis of fine chemicals and pharmaceuticals. ${ }^{30}$ The results were summarized in Table 3. The compounds $\mathbf{1}$ and $\mathbf{2}$ show much higher activity, with $96.41 \%$ and $97.86 \%$ conversion, respectively. Whereas, $\mathbf{3}$ and $\mathbf{4}$ afford lower yields $41.27 \%$ and $77.97 \%$, respectively. However, without the catalyst, the conversion in cyanosilylation of benzaldehyde is only about $29.2 \%$. The above catalytic activities suggest that the Lewis acidity of MOPIP-Gd(III) complex is higher than that of MOPIP$\mathrm{Yb}(\mathrm{III})$ and MOPIP-Sm(III). The different central metal ions probably have a significant influence on the 
reactivity. As a result, MOPIP-Gd(III) complex can be selected as the superior catalyst for cyanosilylation.

\section{Conclusions}

In conclusion, four interesting lanthanide coordination polymers were successfully self-assembled under hydrothermal reaction. Due to the existence of the carboxylate ligands (1,3-BDC and 1,4-BDC) with different steric hindrances, compound 1 shows a zipper chain structure, and 2-4 generate three-dimensional frameworks. Compound 1-4 exhibit strong luminescence in the solid state at room temperature. Additionally, excellent catalytic activities of complexes $\mathbf{1}$ and $\mathbf{2}$ are shown in the cyanosilylation of benzaldehyde, which are responsible not only for strong Lewis acidity but also for its open sites of the central lanthanide ions.

\section{Supplementary Information (SI)}

Crystallographic data for compounds 1-4 have been deposited at the Cambridge Crystallographic Data Centre with the deposition numbers of CCDC 891044, 877862, 885110 and 885680 . Copies of this information may be obtained free of charge from The Director, CCDC, 12 Union Road, Cambridge, CB2 1EZ, UK (fax: +44 1223 336033; e-mail: deposit@ccdc.cam.ac.uk or http://www.ccdc.cam.ac. uk). Luminescent emission spectra of the MOPIP ligand spectra (Figure S1) and of compounds 1-2 (Figure S2) are reported in Supplementary Information, which is available at www.ias.ac.in/chemsci.

\section{Acknowledgements}

This work is supported from the National Natural Science Foundation of China (NO. 21507047), China Postdoctoral Science Foundation (NO. 2015M571695), Postdoctoral Science Foundation of Jiangsu Province (NO. 1401176C) and the Programs of Senior Talent Foundation of Jiangsu University (NO. 14JDG053).

\section{References}

1. Athar M, Li G H, Shi Z, Chen $Y$ and Feng S H 2008 Hydrothermal synthesis and structural characterization of a family of lanthanide tartrates: $[\mathrm{Ln}(2)(\mathrm{C} 4 \mathrm{H} 4 \mathrm{O} 6)(3)(\mathrm{H} 2 \mathrm{O})(3)]$ center dot $1.5 \mathrm{H}(2) \mathrm{O}(\mathrm{Ln}$ $=\mathrm{La}, \mathrm{Ce}, \mathrm{Pr}, \mathrm{Nd}, \mathrm{Sm})$ Solid State Sci. 101853

2. Raja K, Suseelamma A and Reddy K H 2016 Synthesis, X-ray crystal structure, DNA binding and nuclease activity of lanthanide(III) complexes of 2benzoylpyridine acetylhydrazone J. Chem. Sci. 128 1265
3. de Bettencourt-Dias A 2005 Isophthalato-based 2D coordination polymers of $\mathrm{Eu}(\mathrm{III}), \mathrm{Gd}(\mathrm{III})$, and $\mathrm{Tb}(\mathrm{III})$ : Enhancement of the terbium-centered luminescence through thiophene derivatization Inorg. Chem. 442734

4. Bunzli J C G and Piguet C 2005 Taking advantage of luminescent lanthanide ions Chem. Soc. Rev. 341048

5. Sun X J, Li W X, Chai W J, Ren T and Shi X Y 2010 The studies of enhanced fluorescence in the two novel ternary rare-earth complex systems J. Fluoresc. 20453

6. Wang L, Ni L and Yao J 2012 Synthesis, structures and fluorescent properties of two novel lanthanide $[\mathrm{Ln}=\mathrm{Ce}(\mathrm{III}), \operatorname{Pr}(\mathrm{III})]$ coordination polymers based on 1,3-benzenedicarboxylate and 2-(4-methoxyphenyl)1H-imidazo[4,5-f][1,10]phenanthroline ligands J. Solid State Sci. 141361

7. Wang L, Zhao J, Ni L and Yao J 2012 Synthesis, structures, fluorescence properties, and natural bond orbital (NBO) analysis of two metal [Eu-III, Co-II] coordination polymers containing 1,3-benzenedicarboxylate and 2-(4-methoxyphenyl)-1H-imidazo[4,5-f][1, 10]phenanthroline ligands Z. Anorg. Allg. Chem. 638224

8. Che G B, Liu S Y, Zhang Q, Liu C B and Zhang X J 2015 Syntheses, structures and photoluminescence of lanthanide-organic frameworks assembled from multifunctional N,O-donor ligand J. Solid State Chem. 225 378

9. Zang Z G and Tang X S 2015 Enhanced fluorescence imaging performance of hydrophobic colloidal $\mathrm{ZnO}$ nanoparticles by a facile method J. Alloy Compd. 61998

10. Liu H J, Zang Z G and Tang X S 2014 Synthesis mechanism and optical properties of well nanoflower-shaped $\mathrm{ZnO}$ fabricated by a facile method Opt. Mater. Express. 41762

11. Liu B, Zhou S, Li X M and Li C B 2008 A new chainlike copper(II) polymer: [Cu(MOPIP)(BDC)](n)center dot 0.5n(H2O) Chin. J. Struct. Chem. 271195

12. Sheldrick G M SHELXS-97, 1997 In Program for the solution of crystal structures (Göttingen: University of Göttingen)

13. Sheldrick G M SHELXL-97, 1997 In Program for refinement of crystal structures (Göttingen: University of Göttingen)

14. Wan Y G, Zhang L P, Jin L P, Gao S and Lu S Z 2003 High-dimensional architectures from the self-assembly of lanthanide ions with benzenedicarboxylates and 1,10-phenanthroline Inorg. Chem. 424985

15. He J H, Yu J H, Zhang Y T, Pan Q H and Xu R R 2005 Synthesis, structure, and luminescent property of a heterometallic metal-organic framework constructed from rod-shaped secondary building blocks Inorg. Chem. 44 9279

16. Spek A L 1999 In PLATON (Utrecht, The Netherlands: The University of Utrecht)

17. Zhang X J, Xing Y H, Sun Z, Han J, Zhang Y H, Ge M F and Niu S Y 2007 A series of two-dimensional metal-organic frameworks based on the assembly of rigid and flexible carboxylate-containing mixed ligands with lanthanide metal salts Cryst. Growth Des. 7 2041

18. Shi X, Zhu G S, Wang X H, Li G H, Fang Q R, Zhao X J, Wu G, Tian G, Xue M and Wang R W 2005 Polymeric 
frameworks constructed from a metal-organic coordination compound, in 1-D and 2-D systems: Synthesis, crystal structures, and fluorescent properties Cryst. Growth Des. 5341

19. Li J H and Zhang C 2015 Construction of copper-based coordination polymers with $1 \mathrm{D}$ chain, 2D plane and wavy networks: Syntheses, structures, thermal behavior and photoluminescence properties J. Chem. Sci. 1271871

20. Nakamoto K 1986 In Infrared and raman spectra of inorganic and coordination compounds $4^{\text {th }}$ ed. (New York: Wiley Interscience)

21. Shan W W, Ma S S, Wang H L, Li H H, Meng R J and Mei C Z 2014 Synthesis and crystal structure of two coordination polymers assembled from a versatile 4-(4-Hydroxypyridinium-1-yl)phthalic acid J. Inorg. Organomet. Polym. 24468

22. Zhang X J, Li W K, Zhang W T, Che G B, Li X Y, Yu Q and Zhao C C 2015 Hydrothermal syntheses and crystal structures of four novel lanthanide(III) complexes based on two mixed N,O-donor ligands Inorg. Chem. Commun. 51122

23. Ma X, Li X, Cha Y E and Jin L P 2012 Highly Thermostable one-dimensional lanthanide(III) coordination polymers constructed from benzimidazole-5, 6-dicarboxylic acid and 1,10-phenanthroline: Synthesis, structure, and tunable white-light emission Cryst. Growth Des. 125227

24. Lu W G, Yang K, Jiang L, Feng X L and Lu T B 2009 The concentration controlled 1D and 2D supramolecular isomers of lanthanide with 2,2'-bipyridyl-3,3'-dicarboxylate and phenanthroline Inorg. Chim. Acta 3625259
25. Dong D P, Liu L, Sun Z G, Jiao C Q, Liu Z M, Li C, Zhu Y Y, Chen K and Wang C L 2011 Synthesis, crystal structures, and luminescence and magnetic properties of 3D chiral and achiral lanthanide diphosphonates containing left- and right-handed helical chains Cryst. Growth Des. 115346

26. Fomina I G, Dobrokhotova $\mathrm{Z}$ V, Ilyukhin A B, Aleksandrov G G, Kazak V O, Gehman A E, Efimov N N, Bogomyakov A S, Zavorotny Y S, Gerasimova V I, Novotortsev V M and Eremenko I L 2013 Binuclear samarium(III) pivalates with chelating N-donors: Synthesis, structure, thermal behavior, magnetic and luminescent properties Polyhedron 65152

27. Marques L F, Cuin A, de Carvalho G S G, dos Santos M V, Ribeiro S J L and Machado F C 2016 Energy transfer process in highly photoluminescent binuclear hydrocinnamate of europium, terbium and gadolinium containing 1,10-phenanthroline as ancillary ligand Inorg. Chim. Acta 44167

28. Bunzli J C G 2010 Lanthanide luminescence for biomedical analyses and imaging Chem. Rev. 1102729

29. Kajiwara T, Higuchi M, Yuasa A, Higashimura $H$ and Kitagawa S 2013 One-dimensional alignment of strong Lewis acid sites in a porous coordination polymer Chem. Commun. 4910459

30. Zhu Y, Wang Y M, Xu J, Liu P, Weththasinha H A B M D, Wu Y L, Lu X Q and Xie J M 2014 Syntheses, structures, molecular and cationic recognitions and catalytic properties of two lanthanide coordination polymers based on a flexible tricarboxylate J. Solid State Chem. 219259 